\title{
O brincar e suas possibilidades na Educação Infantil: uma revisão sistemática
}

\author{
Play and its possibilities in Childhood Eucation: \\ a systematic review
}

\section{El juego y sus posibilidades en la Educación Infantil:} una revisión sistemática

Paula Marcella Guergolet Brandão' https://orcid.org/0000-0002-8941-7499

Geuciane Felipe Guerim Fernandes² https://orcid.org/0000-0002-8033-656I

\begin{abstract}
Resumo: $O$ presente artigo teve como objetivo investigar o papel da brincadeira como direito fundamental na educação infantil. A Educação Infantil deve ter a finalidade de garantir à criança acesso a aprendizagens de distintas linguagens, assim como o direito à brincadeira, à convivência e à interação com outras crianças. As motivações que encaminharam o interesse pelo assunto buscam analisar a brincadeira como atividade principal da infância e o papel da pré-escola na promoção do brincar. Neste sentido, delineou-se a problemática da pesquisa: Como a brincadeira pode contribuir no processo de humanização das crianças em idade pré-escolar? Trata-se de uma pesquisa bibliográfica do tipo de revisão sistemática, realizada a partir de trabalhos publicados na Biblioteca Digital Brasileira de Teses e Dissertações no período de 2013 a 2018, em diálogo com Costa (2017); Couto (2013); Graciliano (2014); Leontiev (20I0); Lima (2018); Marcolino (2013); Mello (2007); Pasqualini (2013); entre outros, que buscam compreender o desenvolvimento infantil a partir dos fundamentos propostos pela teoria históricocultural. A partir das teses da Teoria Histórico-Cultural, reafirmamos a fundamental importância da educação para o desenvolvimento infantil. Ao compreender que o desenvolvimento acontece por meio da aprendizagem percebe-se que a criança começa aprender a partir do momento que nasce. Em cada estágio do desenvolvimento há uma forma especial de interação da criança com o meio para apropriar-se da cultura e desenvolver-se. Portanto, este trabalho destaca o papel da brincadeira e suas possibilidades na infância
\end{abstract}

Palavras-chave: Brincadeira. Educação Infantil. Criança.

Abstract: This article aimed to investigate the role of play as a fundamental right in early childhood education. Early childhood education should have the purpose of ensure children access to learning in different languages,

\footnotetext{
' Graduada em Pedagogia pela Universidade Estadual do Norte do Paraná (UENP/CCP). Pós-graduação em Educação especial e inclusiva pela UNOPAR. E-mail: paula.marcella97@hotmail.com

${ }^{2}$ Mestre e doutoranda em Educação pela Universidade Estadual de Londrina (UEL). Professora colaboradora da Universidade Estadual do Norte do Paraná (UENP/CCP). E-mail: geuciane@uenp.edu.br
}

Olhar de professor, Ponta Grossa, v. 24, p. I-I8, e-15956.007, 202 I.

Disponível em <https://revistas2.uepg.br/index.php/olhardeprofessor> 
as well as the right to play, to live together and to interact with other children. The motivations that routed to interest in the subject search to analyze play as the main activity of childhood and the role of pre-school in promoting play. In this regard, the research problem was outlined: How can play contribute to the process of humanization of preschool age children? This is a bibliographic search of the type of systematic review, carried out based on works published in the Brazilian Digital Library of Theses and Dissertations from 2013 to 2018, in dialogue with Costa (20I7); Couto (20I3); Graciliano (20I4); Leontiev (20I0); Lima (20I8); Marcolino (20I3); Mello (2007); Pasqualini (20I3); among others, that search to understand child development from the foundations proposed by historical-cultural theory. Based on the theses of the Historical-Cultural Theory, we reaffirm the fundamental importance of education for child development. By understanding that development happens through learning it is clear that the child starts to learn from the moment he is born. At each stage of development there is a special way for the child to interact with the environment to appropriate the culture and develop. Therefore, this study highlights the role of play and its possibilities in childhood.

Keywords: Play. Childhood education. Child.

Resumen: Este artículo tuvo como objetivo investigar el papel del juego como un derecho fundamental en la educación de la primera infancia. La educación de la primera infancia debe tener el propósito de garantizar a los niños el acceso al aprendizaje en diferentes idiomas, así como el derecho a jugar, vivir juntos e interactuar con otros niños. Las motivaciones que llevaron al interés en el tema buscan analizar el juego como la actividad principal de la infancia y el papel del preescolar en la promoción del juego. En este sentido, se planteó el problema de investigación: cómo puede contribuir el juego al proceso de humanización de los niños en edad preescolar? Esta es una búsqueda bibliográfica del tipo de revisión sistemática, realizada en base a trabajos publicados en la biblioteca digital brasileña de tesis y disertaciones de 2013 a 2018, en diálogo con Costa (20I7); Couto (20I3); Graciliano (20I4); Leontiev (20I0); Lima (20I8); Marcolino (20I3); Mello (2007); Pasqualini (20I3); entre otros, que buscan entender el desarrollo infantil a partir de los fundamentos propuestos por la teoría histórico-cultural. Sobre la base de las tesis de la teoría histórico-cultural, reafirmamos la importancia fundamental de la educación para el desarrollo infantil. Al comprender que el desarrollo ocurre a través del aprendizaje, queda claro que el niño comienza a aprender desde el momento en que nace. En cada etapa de desarrollo hay una forma especial para que el niño interactúe con el entorno para apropiarse de la cultura y desarrollarse. En este sentido, este trabajo destaca el papel del juego y sus posibilidades en la infancia.

Palabras-clave: Jugar. Educación Infantil. Niño.

\section{Introdução}

Os estudos desenvolvidos a partir da Teoria Histórico-Cultural demonstram a importância da educação para o desenvolvimento da criança como um sujeito histórico e de direitos. Sabendo que a aprendizagem se inicia desde o momento que a criança nasce, é importante proporcionar a ela o acesso a diferentes vivências e interações que contribuem para o seu desenvolvimento. Nesse sentido, o presente artigo busca analisar o papel da brincadeira como direito fundamental na Educação Infantil. A temática do estudo justifica-se pela necessidade de repensar o papel da brincadeira na infância, a fim de contribuir com o desenvolvimento da criança. Com o objetivo de investigar esse assunto, realizamos uma pesquisa bibliográfica do tipo de revisão sistemática, em diálogo com os fundamentos propostos pela Teoria Histórico-Cultural, que compreendem a brincadeira como atividade principal na infância e a pré-escola como momento propulsor de desenvolvimento. Assim, delineamos o seguinte questionamento: "Como a brincadeira pode contribuir no processo de humanização das crianças em idade pré-escolar?". 
Inicialmente, constatamos que as intervenções educativas devem garantir direitos primordiais da infância, como o tempo de brincar, criar, pensar, movimentar, expressar, comunicar, cantar e expressar sentimentos. Muitas vezes, as primeiras manifestações de linguagem acontecem por meio da brincadeira, repleta de sentidos concedidos pela criança, que planeja e manifesta suas ações no ambiente em que vive (COUTO, 20I3; LIMA; AKURI; VALIENGO, 20I8).

\begin{abstract}
É nesse cenário propício para repensarmos práticas pedagógicas na Educação Infantil que se fortalecem discussões sobre a educação escolar como processo único e singular para a formação das qualidades humanas nas pessoas, considerando as brincadeiras infantis como atividades a serem potencializadas nas escolas da infância por se constituírem como condições efetivas de envolvimento emocional e psíquico de cada criança em seu processo de humanização. Como acenam artigos e incisos em resoluções e pareceres legais brasileiros, trata-se de ações educativas que visem garantir um dos direitos fundamentais da infância brasileira: o tempo de estar na escola para ser criança e viver plenamente os anos iniciais da vida, brincando, criando, pensando, se movimentando, se expressando, comunicando ideias e sentimentos, cantando, pulando, correndo, subindo e descendo de árvores (AKURI; LIMA; VALIENGO, 2018, p. 362).
\end{abstract}

Diante disso, ressaltamos a importância da Educação Infantil como um espaço que deve possibilitar o desenvolvimento das crianças de até seis anos de idade, propiciando condições necessárias para o desenvolvimento das máximas capacidades humanas, que desde o nascimento são importantes mediante a atividade vivenciada socialmente pelas crianças (GRACILIANO, 20I4; LEONTIEV, 20I0; MELLO, 2007).

Nos estudos de Pasqualini $(2009,2013)$ são apresentadas as principais atividades que norteiam o desenvolvimento humano a partir da Teoria Histórico-Cultural: a comunicação emocional direta do bebê, a atividade objetal manipulatória, o jogo de papéis ou brincadeira de faz de conta, a atividade de estudo, a comunicação íntima pessoal e a atividade profissional. Neste estudo, destacamos a atividade de jogo de papéis/faz de conta, que corresponde à idade da criança na Educação Infantil, etapa escolar obrigatória. Para isso, realizamos uma busca de trabalhos cadastrados junto à base de dados da Biblioteca Digital Brasileira de Teses e Dissertações (BDTD), a fim de obter um parâmetro nacional sobre a temática em questão.

Os resultados demonstram que as práticas, tempos e espaços de brincar na Educação Infantil precisam ser planejados. Ao invés de encurtar a infância mediante práticas que antecipam a escolarização, torna-se necessário repensá-las e aprimorá-las para garantir, em cada momento da vida da criança, as vivências essenciais para o seu desenvolvimento humano.

Olhar de professor, Ponta Grossa, v. 24, p. I-18, e-15956.007, 2021.

Disponível em <https://revistas2.uepg.br/index.php/olhardeprofessor> 


\section{A Educação Infantil como possibilidade para o desenvolvimento da criança}

A criança é um sujeito histórico e de direitos. Ao se relacionar com o meio, ela constrói sua identidade pessoal e coletiva, brincando, imaginando, aprendendo, observando e questionando. Devido à sua capacidade de estabelecer relações com o mundo ao redor, torna-se importante viabilizar o acesso às diferentes manifestações culturais, possibilitando o enriquecimento máximo das vivências que lhe são propostas (PASQUALINI, 2009; MELLO, 2007).

A Educação Infantil ofertada em creches e pré-escolas é definida nas Diretrizes Curriculares da Educação Infantil como um espaço institucional, que concebe instituições públicas e/ou privadas que educam e cuidam de crianças de zero a cinco anos de idade. Tal espaço é organizado e fiscalizado pelo órgão competente do sistema de ensino, logo, é dever do Estado garantir a sua oferta (BRASIL, 20I0).

No documento "Critérios para um atendimento em creches que respeite os direitos fundamentais das crianças" (CAMPOS; ROSEMBERG, 2009) encontramos um caminho necessário para a escola da educação infantil. $O$ documento apresentado explicita de forma clara aquilo que é de direito das crianças pequenas vivenciarem:

\footnotetext{
Nossas crianças têm direito à brincadeira

Nossas crianças têm direito à atenção individual

Nossas crianças têm direito a um ambiente aconchegante, seguro e estimulante

Nossas crianças têm direito ao contato com a natureza

Nossas crianças têm direito a higiene e à saúde

Nossas crianças têm direito a uma alimentação sadia

Nossas crianças têm direito a desenvolver sua curiosidade, imaginação e capacidade de expressão

Nossas crianças têm direito ao movimento em espaços amplos

Nossas crianças têm direito à proteção, ao afeto e à amizade

Nossas crianças têm direito a expressar seus sentimentos

Nossas crianças têm direito a uma especial atenção durante seu período de adaptação à creche

Nossas crianças têm direito a desenvolver sua identidade cultural, racial e religiosa (CAMPOS; ROSEMBERG, 2009, p. 13).
}

A proposta pedagógica da Educação Infantil deve garantir à criança o acesso a aprendizagens de distintas linguagens, assim como o direito à brincadeira, à convivência e à interação com outras crianças. Os eixos "interações" e "brincadeiras" são necessários e orientam o trabalho nessa etapa de escolarização, por meio do desenvolvimento das experiências sensoriais, expressivas e corporais que promovam movimentação ampla, respeitando o espaço, os ritmos e o desenvolvimento da criança. Sendo assim, é papel da escola incentivar a curiosidade, a exploração, o encantamento, o questionamento e o conhecimento das crianças, no que se refere ao mundo físico e social, provocando o contato e interação com diversas manifestações e expressões (BRASIL, 20I0). 
Os estudos da Teoria Histórico-Cultural apontam que a aprendizagem impulsiona o desenvolvimento. Para os pesquisadores dessa vertente teórica, é necessário identificar as condições apropriadas para a aprendizagem, abrangendo desde a formação dos professores da Educação Infantil até a compreensão do papel da ação educativa desses profissionais no processo de humanização das crianças pequenas (MELLO, 2007).

Em cada momento da vida, há uma melhor forma pela qual a criança se relaciona com o mundo, produzindo sentidos ao que vivencia. Ao invés de limitar a infância mediante práticas que precipitam a escolarização infantil, torna-se necessário repensar os conteúdos e métodos educativos para garantir, em cada etapa, as vivências fundamentais para o desenvolvimento integral da criança. Desse modo, é importante refletir sobre como as práticas pedagógicas na Educação Infantil podem estabelecer condições concretas de envolvimento emocional e psíquico de cada criança em seu processo de humanização (COUTO, 2013; LIMA; AKURI; VALIENGO, 20I8). "Para a teoria histórico-cultural, as crianças aprendem quando são sujeitos das situações vividas. Isto, na escola da infância - na creche requer que organizemos o espaço, o tempo, as relações e as atividades de modo a promover esse agir das crianças [...]” (MELLO, 2017, p. 4I).

Ao analisar as Diretrizes Curriculares Nacionais para a Educação Infantil (BRASIL, 20I0), notase que as ações educativas devem garantir direitos essenciais da infância, como o tempo de brincar, criar, pensar, movimentar, expressar, comunicar, cantar e expressar sentimentos. Muitas vezes, as primeiras manifestações de linguagem ocorrem por meio da brincadeira, repleta de sentidos concedidos pelas crianças, os quais possibilitam que elas planejem e manifestem suas ações no espaço em que vivem (COUTO, 20I3; LIMA; AKURI; VALIENGO, 20I8).

O processo de desenvolvimento da criança é compreendido a partir de sua participação no meio social. É necessário analisar como ela participa das atividades na Educação Infantil, verificar se tais atividades têm significado para ela, a fim de que suas qualidades humanas sejam desenvolvidas ao longo desse percurso (COSTA; MELLO, 2017).

\begin{abstract}
O processo pedagógico - mediado pelas distintas linguagens - requer um trabalho cuidadosamente planejado, sistemático e intencional, para que possa cumprir o papel de promover o desenvolvimento das linguagens infantis. E mais, deve ocorrer, na creche, tendo por base uma multiplicidade de interações: entre as crianças, entre nós e as crianças, com as famílias, com a comunidade. [...] É preciso que haja interação pedagógica de nossa parte, professoras e professores, mediadores das primeiras apropriações de bebês e crianças pequenas nesse espaço (NOGUEIRA, 2017, p. III).
\end{abstract}

Dessa maneira, apontamos a importância de inserir a criança na pré-escola, bem como de considerar e caracterizar esse espaço como um local onde ela se relaciona, brinca, imagina, assume papéis, aprende e se desenvolve (GRACILIANO, 20I4; LEONTIEV, 20I0; MELLO, 2007). A pré-escola necessita se tornar um lugar de pertencimento e direitos garantidos em cada momento da infância. 
Para isso, destacamos a relevância dos estudos do desenvolvimento humano na perspectiva da Teoria Histórico-Cultural.

\section{Atividade principal: a brincadeira e suas possibilidades na pré-escola}

As teses da Teoria Histórico-Cultural reafirmam a fundamental importância da educação na vida da criança. Ao compreender que o desenvolvimento acontece por meio da aprendizagem, percebe-se que ela começa aprender a partir do momento que nasce. Além disso, em cada etapa da vida, destaca-se uma forma especial de interação da criança com o meio para apropriar-se da cultura e desenvolver-se (MELLO, 2017).

A partir da perspectiva Histórico-Cultural analisa-se o desenvolvimento humano, destacando que a comunicação com os adultos é necessária para o processo de humanização infantil. Em cada fase, uma atividade principal se constitui como a melhor forma da criança se relacionar com a realidade. Por meio dessa atividade, os processos psíquicos particulares tomam significado e podem ser reestruturados. Logo, a atividade principal estabelece uma relação viva entre a criança e sua realidade (LEONTIEV, 20I0).

Os estudos de Pasqualini $(2009,2013)$ apresentam as principais atividades que norteiam o desenvolvimento humano, com base na Teoria Histórico-Cultural: a comunicação emocional direta do bebê, a atividade objetal manipulatória, o jogo de papéis ou brincadeira de faz de conta, a atividade de estudo, a comunicação íntima pessoal e a atividade profissional. Neste estudo, nos detemos na atividade de jogo de papéis/faz de conta, que corresponde à etapa escolar obrigatória da criança na Educação Infantil.

Desde o nascimento do bebê, surge a necessidade de atenção e cuidado por parte dos adultos. Com o tempo, outro tipo de relação vai se constituindo entre os dois, colocando a criança em novas relações. A comunicação do bebê se inicia por meio do choro, de gritos, gestos e movimentos. $O$ adulto provoca na criança a necessidade de comunicar-se, atividade concebida como comunicação emocional direta com o adulto (PASQUALINI, 2009, 20I3).

\footnotetext{
Quando olhamos para o bebê procurando o que ele é capaz de fazer - em vez de olhar para aquilo que ele ainda não consegue fazer -, percebemos como ele se relaciona com o mundo por meio do olhar, do gesto, do movimento, por meio daquilo que pega, olha, leva à boca, $O$ bebê sente o mundo e se comunica por meio do seu corpo; suas sensações confundem percepção com emoção. Por isso é tão importante a forma como a pessoa adulta toca o bebê, como anuncia ao bebê sua presença e sua intenção antes de tocá-lo, de tirá-lo do berço ou do chão, de trocálo de ambiente, de interromper aquilo que ele está fazendo. Mesmo o bebê não entendendo exatamente $\circ$ que a pessoa adulta fala, sabe que algo vai acontecer com ele e se prepara para isso (MELLO, 2017, p. 43).
}

Olhar de professor, Ponta Grossa, v. 24, p. I-19, e-15956.007, 2021.

Disponível em <https://revistas2.uepg.br/index.php/olhardeprofessor> 
Durante o primeiro ano de vida, por meio das trocas afetivas entre o adulto e o bebê, iniciase a formação do processo de comunicação. Em consequência disso, o adulto apresenta objetos à criança, contribuindo para a apropriação de ações sensório-motoras. Ao final do primeiro ano até por volta dos três anos, na primeira infância, com a apropriação da linguagem, a criança começa a perceber os objetos, dando sentido social, período marcado pelo desenvolvimento da atividade objetal manipulatória. Nesse período, a escola da infância tem o papel de ampliar o repertório das crianças, bem como os recursos didáticos como possibilidade de promover novas aprendizagens.

Um exemplo, para ilustrar possibilidades da escola nesse período do desenvolvimento:

Um exemplo, para ilustrar a correspondência desse período do desenvolvimento, em que as ações com objetos impulsionam aprendizagens, mas que precisam ser direcionadas em articulação com os objetivos- conteúdos-metodologias, pode ser a construção de uma horta coletiva, em algum espaço externo da sala de aula. Vejamos as possíveis relações e ações de ensino que podem ser desencadeadas: a partir da área de conhecimento - ciências da natureza -, ao trabalhar o conteúdo plantas, para além de classificar, pintar ou observar, é possível enriquecer a forma de ensinar com a preparação e manuseio da terra, com as mãos e com os instrumentos próprios, manusear sementes, raízes, folhas, frutos; selecionar quais plantas podem ser plantadas, o que precisarão para crescer e se desenvolver, propor experiências, instigar a curiosidade das crianças por meio de perguntas desencadeadoras que impulsionem o levantamento de hipóteses e movimentem seu pensamento na ação com os recursos que estão sendo disponibilizados e, intencionalmente, provocadas a manipular. Essas ações de aprendizagem permitem conquistas qualitativamente novas, em termos de funções psíquicas, como sensações, percepção, memória, entre outras, como também propicia aproximações com os fenômenos da natureza, suas transformações, suas leis, provocando na criança, ações de manipulação direcionada por conteúdos que instigam novos interesses e novos motivos (LAZARETTI; MELLO, 2018, p. 126).

Inicialmente, a relação se dava entre a criança e o adulto social, agora, o destaque é na relação entre a criança e o objeto social, a qual é mediada pelo adulto. $O$ objeto é repleto de significação social e por isso necessita da participação do adulto que apresenta os modos sociais de ação dos instrumentos produzidos pela cultura. Essa atividade é formada pelo contato com os instrumentos e a aplicação de palavras para manifestar desejos. A linguagem retrata a linha central de desenvolvimento dessa idade e, devido a ela, a criança tem relações diferentes com o meio social. Contudo, tanto o desenvolvimento da assimilação quanto o da linguagem estão rigorosamente relacionados entre si nessa fase. Sendo assim, é fundamental a relação com o papel do adulto mediador, não como alguém que apenas fornece à criança objetos para uso livre, mas que medeia o processo de apropriação desses objetos, apresentando as formas sociais de ação de cada um deles (LAZARETTI; MELLO, 20I8; MELLO, 2007; PASQUALINI, 2009, 2013).

Trata-se de um período em que tem preponderância o desenvolvimento da esfera das possibilidades operacionais técnicas da criança. $O$ que está em questão é assimilar os modos socialmente elaborados de ações com objetos. Se anteriormente tinha 
centralidade a relação criança-adulto social, mediada pelos objetos, agora ganha destaque a relação criança-objeto social (mundo das coisas), mediada pelo adulto (PASQUALINI, 2013, p. 85).

"Com ações de ensino desencadeadoras de ações de aprendizagem, ao manipular os objetos, elementos da natureza e da cultura humana, na criança produzem-se interesses cada vez mais complexos e ela anseia compreender as relações entre as pessoas e suas funções sociais" (LAZARETTI; MELLO, 2018, p. 127). Assim, aproximadamente dos três até aos seis/sete anos, ao se apropriar da função social do objeto, a criança passa a ter interesse pelo sentido social das ações e pelas relações sociais que os objetos da cultura são utilizados pelo adulto.

A brincadeira de papéis é a atividade na qual a criança experimenta fazer ações que o adulto faz, e agir com os objetos da maneira que $o$ adulto age. $O$ que caracteriza essa atividade como lúdica é o fato de que seu foco não está no resultado da ação, mas sim na ação em si mesma e no próprio processo. Ao analisar a brincadeira de casinha, é possível perceber que a criança recorda os acontecimentos que marcam sua relação com seu meio e o modo como os objetos têm significado na vida social (COUTO, 20I3; PASQUALINI, 20I3).

Para garantir esses saltos qualitativos no desenvolvimento da criança nesse período do desenvolvimento, as ações de ensino devem ser direcionadas para enriquecer o repertório de conhecimento, vivências e experiências das e nas relações humanas, como também produzir novos interesses e motivos para outras esferas de conhecimento da realidade humana, ou seja, os conteúdos de ensino. Voltemos ao exemplo anterior, a horta coletiva. As conquistas do desenvolvimento provocam novas relações com esse mesmo recurso didático. Nesse período, a criança, além de manipular as ferramentas de jardinagem e outros instrumentos, manusear sementes, plantas, raízes, pode assumir o papel do jardineiro, do agricultor e compreender todas as ações e operações dessa função social, como também e, concomitantemente, a compreensão com o conteúdo plantas alcança novas e complexas relações e se convertem em novas ações de aprendizagem. Ao aprender sobre as plantas, para além de percepções imediatas, a criança começa a estabelecer relações sobre esses fenômenos naturais, que movimentam seu pensamento, conduzem-na a levantar hipóteses, procurar respostas, fomentar dúvidas e instigar a curiosidade pelo mundo (LAZARETTI; MELLO, 2018, p. 129).

Nesse momento a criança manifesta o desejo de compreender o mundo que a cerca e isso nos faz refletir sobre o processo de ensino na educação infantil. Os estudos de Lima, Akuri e Valiengo (2018).demonstram que, nessa fase do desenvolvimento psíquico, o papel fundamental do professor é possibilitar que as crianças conheçam e reconheçam o mundo à sua volta, planejando espaços, tempos, materiais e relacionamentos, de forma a garantir o direito à brincadeira.

Ao observar a organização do espaço para brincar, percebe-se que a maior parte das atividades realizadas na escola é determinada pelos professores, referente a registros em cadernos e a jogos apresentados como pedagógicos. Frequentemente, muitos dos momentos vividos por adultos e crianças no âmbito escolar são cumpridos para ocupar o tempo dos pequenos. Desse modo, notamos 
que o tempo para brincar é curto e infrequente. Trata-se de um cenário preocupante, que prejudica o aprendizado e o desenvolvimento infantil, pois em todo o momento que a criança brinca, ela se desenvolve (LIMA; AKURI; VALIENGO, 20I8).

Diante disso, muitas das práticas pedagógicas não possibilitam tempo e momentos para que a criança viva a infância, aprenda e se humanize. Uma pesquisa realizada por Lima, Akuri e Valiengo (2018) demonstra que a criança é concebida e tratada como aluna, ao passo que a infância é vista como uma etapa que prepara para o Ensino Fundamental. As crianças só podem levar seus brinquedos para a escola uma vez por semana, o que indica que elas quase não brincam e têm poucos momentos para desenvolver suas expressões. Muitos dos materiais/brinquedos ficam guardados em armários e, normalmente, os materiais acessíveis são aqueles que interessam aos professores. Mesmo diante dessa situação alarmante, as professoras participantes do estudo apontam que a brincadeira é necessária na Educação Infantil e que, por meio dessas atividades, as crianças aprendem e se desenvolvem com maior prazer (LIMA; AKURI; VALIENGO, 20I8).

É importante destacar, ainda, de que modo se organizam os momentos de brincar nas escolas de Educação Infantil, os quais requerem organização para que as crianças tenham a oportunidade de escolher seus pares, brinquedos, jogos e objetos, bem como espaços que permitam brincar. Por esse motivo, a presença do professor não deve ser determinada para limitar o comportamento das crianças, mas sim para observar como elas brincam, se relacionam, escolhem, se movimentam, e assim, compartilhar desses momentos, para que elas exerçam o papel assumido na brincadeira. Portanto, a brincadeira de papéis como atividade principal na Educação Infantil permite momentos livres e espaços para brincar, dessa forma, gera novos interesses e necessidades nas crianças (LAZARETTI; MELLO, 2018).

Por isso, é tarefa da escola de educação infantil ampliar o círculo de contatos com a realidade da criança. É tarefa do professor transmitir à criança conhecimentos sobre o mundo, não só porque a criança tem direito a conhecer o mundo em que vive para além dos limites estreitos da sua experiência individual, mas porque esses conhecimentos serão justamente a matéria-prima da brincadeira infantil (PASQUALINI, 2013, p. 90).

A partir da brincadeira de faz de conta, as crianças dividem seus papéis e os representam por meio de atitudes que manifestam o sentido da ação do personagem. As funções desenvolvidas na atividade com os adultos tornam-se lúdicas quando a criança transmite o uso de um objeto assimilado em uma ação para outras atividades. Assim, a apresentação e desenvolvimento do papel dão significado a essas ações e às relações entre as pessoas nas atividades humanas. Consequentemente, a brincadeira de papéis sociais está relacionada aos modos de relacionamento entre as pessoas e, no decorrer da 
brincadeira, pode acontecer a mudança do tema representado (MARCOLINO, 20I3; MELLO, 2007; PASQUALINI, 2009).

Ao longo do desenvolvimento da brincadeira, é preciso dar condições para que apareçam novos temas e levar em consideração os brinquedos que são ofertados, assim como a preparação do espaço para as crianças. Para algumas crianças mais novas, o significado da brincadeira é desempenhar as ações dos papéis, já para as crianças mais velhas é simbolizar as relações pessoais do papel. Então, através da brincadeira, a criança reconhece e compreende a atividade humana e as relações sociais, e o professor passa a ser o personagem fundamental na apresentação dos conteúdos e na discussão dos papéis (MARCOLINO, 20I3).

\section{Procedimentos metodológicos}

A fim de aprofundar na temática de estudo, realizamos uma pesquisa bibliográfica que, segundo Gil (2002), é desenvolvida com materiais já prontos - formados, principalmente, de livros e artigos científicos - em busca de obter fundamento teórico, bem como investigar fontes bibliográficas confiáveis e científicas.

Essa pesquisa de cunho bibliográfico define-se como do tipo de revisão sistemática. De acordo com Galvão, Sawada e Trevizan (2004), a revisão sistemática corresponde a uma pergunta evidentemente formulada, que utiliza métodos sistemáticos e explícitos para reconhecer, selecionar e avaliar criticamente pesquisas importantes, como também coletar e analisar dados de estudos incluídos na revisão.

Os procedimentos metodológicos adotados nessa pesquisa foram organizados com o intuito de promover o seu direcionamento. Para isso, consideramos os trabalhos cadastrados junto à base de dados da Biblioteca Digital Brasileira de Teses e Dissertações (BDTD), a fim de obter um parâmetro nacional sobre o tema em questão.

Com a finalidade de reconhecer a importância dessa discussão e considerar os trabalhos já publicados, realizamos uma revisão sistemática de literatura na base de dados da BDTD, focalizando os estudos relacionados à garantia do brincar na etapa da Educação Infantil. Por essa razão, o período selecionado foi de 2013 a 2018 , considerando a mudança do cenário nacional da Educação Infantil no ano de 20I3. A partir desse ano, intensificou-se a expansão dessa etapa da educação, promovida pela Lei $n^{\circ}$ 12.796, de 4 de abril de 2013 (BRASIL, 20I3), que estabelece a obrigatoriedade de matrículas para crianças com quatro e cinco anos.

Olhar de professor, Ponta Grossa, v. 24, p. I-19, e-15956.007, 202 I.

Disponível em <https://revistas2.uepg.br/index.php/olhardeprofessor> 


\section{Resultados e discussões}

Inicialmente, realizamos um levantamento em busca de dissertações e teses que apresentassem, no título da publicação, os descritores "jogo de papéis sociais", "brincadeira de papéis sociais", "brincadeira de faz de conta" e "brincar de faz de conta". Para a análise, selecionamos os trabalhos que se referem à etapa da Educação Infantil.

Ao utilizar o descritor "jogo de papéis sociais", obtivemos uma dissertação (MANICA, 2018) e não encontramos nenhuma tese. Na busca com o descritor "brincadeira de faz de conta", obtivemos uma dissertação (ABOUD, 20I8) e uma tese (AMBRA, 20I8). Já com o descritor "brincar de faz de conta", encontramos quatro dissertações e nenhuma tese. Comprovamos que, dos quatro trabalhos encontrados, três não remetiam ao foco da pesquisa, visto que eram referentes a movimentos sociais e tratamentos de saúde. Assim, restou apenas um trabalho com foco no brincar de faz de conta na Educação Infantil (SILVA, 2017).

Por fim, ao realizar a busca com o descritor "brincadeira de papéis sociais", não encontramos dissertações e obtivemos duas teses, as quais remetiam ao foco das brincadeiras de papéis sociais na Educação Infantil (GOBBO, 20I8; MARCOLINO, 20I3).

Ao cruzar as publicações encontradas, constatamos que não houve repetição de pesquisas com estes buscadores, tanto nas dissertações quanto nas teses. Assim, os trabalhos para a discussão encontram-se nos quadros abaixo e serão analisados de acordo com seus descritores:

Quadro I: Dissertação com o descritor jogo de papéis sociais, com foco na Educação Infantil.

\begin{tabular}{|l|l|l|l|l|}
\hline Título & Autor & IES & Ano & $\begin{array}{l}\text { Metodologia } \\
\text { Quantitativa/qualitativa }\end{array}$ \\
\hline $\begin{array}{l}\text { Brincar/jogo de papéis sociais } \\
\text { e a educação infantil à luz da } \\
\text { psicologia histórico-cultural }\end{array}$ & Manica, Ana Paula & UFG & 2018 & Qualitativa \\
\hline
\end{tabular}

Fonte: As autoras, 2019.

Quadro 2: Dissertação com o descritor brincadeira de faz de conta, com foco na Educação Infantil.

\begin{tabular}{|l|l|l|l|l|}
\hline Título IES & Autor & Ano & $\begin{array}{l}\text { Metodologia } \\
\text { Quantitativa/qualitativa }\end{array}$ \\
\hline $\begin{array}{l}\text { Os cantos estão arrumados. e } \\
\text { agora, professora? O papel } \\
\text { docente nas brincadeiras de } \\
\text { faz de conta com crianças da } \\
\text { Educação Infantil }\end{array}$ & $\begin{array}{l}\text { Oboud, Leila } \\
\text { Orssolan }\end{array}$ & PUC & 2018 & Qualitativa \\
& & & & \\
\hline
\end{tabular}

Fonte: As autoras, 2019.

Olhar de professor, Ponta Grossa, v. 24, p. I-18, e-15956.007, 202 I.

Disponível em <https://revistas2.uepg.br/index.php/olhardeprofessor> 
Quadro 3: Dissertação com o descritor brincar de faz de conta, com foco na Educação Infantil.

\begin{tabular}{|l|l|l|l|l|}
\hline Título & Autor & IES & Ano & $\begin{array}{l}\text { Metodologia } \\
\text { Quantitativa/qualitativa }\end{array}$ \\
\hline $\begin{array}{l}\text { O brincar de faz de conta da } \\
\text { criança com autismo: um } \\
\text { estudo a partir da perspectiva } \\
\text { histórico-cultural }\end{array}$ & $\begin{array}{l}\text { Silva, Maria } \\
\text { Angélica da }\end{array}$ & UnB & 2017 & Qualitativa \\
\hline
\end{tabular}

Fonte: As autoras, 2019.

A partir das referências organizadas nos quadros I, 2 e 3 e nos limites deste texto, articulamos aspectos das dissertações encontradas nos três descritores, com o objetivo de compreender as aproximações e distanciamentos referentes à garantia do brincar como direito fundamental da criança.

Em "Brincar/jogo de papéis sociais e a Educação Infantil à luz da psicologia histórico-cultural", Manica (2018) analisa o brincar na Educação Infantil e nos documentos norteadores do município de Catalão/GO por meio da Teoria Histórico-Cultural. Com essa análise, foi possível destacar dois pontos que foram considerados fundamentais: o primeiro diz respeito ao brincar/jogo de papéis sociais como uma construção histórica e cultural, e não algo natural e espontâneo, ao passo que o segundo está relacionado aos documentos oficiais que destacam a importância do brincar, porém, numa perspectiva construtivista. Quanto ao papel do educador, o autor aponta a relevância do planejamento das atividades na Educação Infantil, destacando que, quando intencionalmente planejadas e mediadas pelo professor, contribuem para o desenvolvimento da criança.

A criança, com a ajuda do adulto, não somente aprende a conhecer os aspectos exteriores da ação que ela busca imitar, mas também aprende a importância e o significado social que tem a atividade que ela imita, a atitude dos adultos para com ela e o modo como se organizam suas atividades (MOYA, D.; SFORNI; MOYA, P., 2019, p. 125).

Aboud (20I8) identifica o que os professores sabem sobre a brincadeira de faz de conta e como estão organizadas as situações para essa brincadeira na Educação Infantil, a fim de desenvolver e promover a aprendizagem das crianças. A pesquisa evidenciou a necessidade dos professores discutirem sobre os momentos de brincadeiras, com base nas teorias que consideram a aprendizagem e o desenvolvimento da criança, bem como o papel do professor como mediador.

Concordamos com Pasqualini (2013, p. 90) que "[...] o potencial de promover desenvolvimento psíquico da brincadeira depende da riqueza do acesso ao conhecimento sobre o mundo que a criança tem (ou não)". A autora complementa ainda que "o conteúdo dos jogos dramatizados das crianças e o desenvolvimento psíquico que será conquistado por meio dessa atividade dependem de suas condições de vida e de educação" (PASQUALINI, 20I3, p. 90). 
Nesse contexto, destacam-se os estudos de Graciliano (20l4), Mello (2007) e Leontiev (2010), os quais consideram que o desenvolvimento da criança ocorre a partir de sua realidade e pela atividade principal. Os autores também apontam que, nesse período, o brincar é a atividade principal, consequentemente, $\circ$ adulto deve organizar e planejar situações para contribuir para $\circ$ desenvolvimento da criança, de modo que ela estabeleça relações com o meio e com os colegas.

Para imitar as ações dos adultos, a criança imagina situações, observa atentamente seus modos de agir e os objetos utilizados por eles, e estabelece relações de raciocínio entre as ações empreendidas, enfim, mobiliza funções psíquicas como a imaginação, a atenção voluntária, a percepção e o pensamento (DE JESUS MOYA; SFORNI; MOYA, 2019, p. I31).

O trabalho de Silva (2017), intitulado "O brincar de faz de conta da criança com autismo: um estudo a partir da perspectiva histórico-cultural" tem o objetivo de analisar o brincar da criança com autismo, destacando os recursos simbólicos em desenvolvimento no brincar de faz de conta, como o uso do objeto pivô e a configuração dos jogos de papéis. Os resultados demonstram que essas crianças brincam, criam, imaginam e assumem papéis. Ademais, os dados empíricos revelaram distintas situações lúdicas vivenciadas por elas, tanto sozinhas quanto na relação com o outro, demonstrando que elas realizam ações mais vinculadas aos objetos. Dito de outra maneira, suas ações lúdicas são determinadas pelos objetos. Sendo assim, o autor aponta a necessidade de mediações planejadas frente ao jogo de papéis, que é um elemento central para o desenvolvimento dessas crianças. Nessa lógica, constatamos a relevância do adulto na organização de situações para a brincadeira. Os estudos de Marcolino (2013) completam a constatação de que a brincadeira de papéis é muito importante para o desenvolvimento da criança, pois permite que ela assuma atitudes do papel do outro, a partir do meio social em que está inserida.

Frente às expressões de busca, também encontramos teses que apresentam os referidos buscadores, as quais estão organizadas nas tabelas abaixo:

Quadro 4: Teses com o descritor brincadeira de papéis sociais, com foco na Educação Infantil.

\begin{tabular}{|l|l|l|l|l|}
\hline Título Autor & IES & Ano & $\begin{array}{l}\text { Metodologia } \\
\text { Quantitativa/qualitativa }\end{array}$ \\
\hline $\begin{array}{l}\text { A mediação pedagógica na } \\
\text { educação infantil para o } \\
\text { desenvolvimento da } \\
\text { brincadeira de papéis sociais }\end{array}$ & Marcolino, Suzana & UNESP & 2013 & Qualitativa \\
\hline $\begin{array}{l}\text { O desenvolvimento da } \\
\text { imaginação infantil mediado } \\
\text { por gêneros discursivos e } \\
\text { objetivado em desenhos e } \\
\text { brincadeiras de papéis sociais }\end{array}$ & Rossler Rodrigues & & & \\
\hline
\end{tabular}

Fonte: As autoras, 2019.

Olhar de professor, Ponta Grossa, v. 24, p. I-18, e-15956.007, 2021.

Disponível em <https://revistas2.uepg.br/index.php/olhardeprofessor> 
Quadro 5: Tese com o descritor brincadeira de faz de conta, com foco na Educação Infantil.

\begin{tabular}{|l|l|l|l|l|}
\hline Título Autor & IES & Ano & $\begin{array}{l}\text { Metodologia } \\
\text { Quantitativa/qualitativa }\end{array}$ \\
\hline $\begin{array}{l}\text { A avaliação da brincadeira de } \\
\text { faz de conta por meio do } \\
\text { ChIPPA: perspectivas para a } \\
\text { prática pedagógica na } \\
\text { Educação Infantil }\end{array}$ & & PUC & 2018 & Qualitativa \\
\hline
\end{tabular}

Fonte: As autoras, 2019.

No trabalho "A mediação pedagógica na educação infantil para o desenvolvimento da brincadeira de papéis sociais", Marcolino (2013) investiga a mediação pedagógica executada a partir do desenvolvimento da brincadeira de papéis sociais, com foco na Teoria do Jogo de Elkonin. $O$ autor considera que as brincadeiras de papéis sociais têm papel muito importante no desenvolvimento da atividade guia da infância. Por esse motivo, formulou a tese de que as ações e intervenções que incidem diretamente sobre o papel, unidade de análise da brincadeira e também objeto de intervenção do professor, são as que provocam as transformações fundamentais da brincadeira de papéis sociais que mais caracterizam seu desenvolvimento.

Segundo De Jesus Moya, Sforni e Moya (2019) não basta o professor observar e apresentar diferentes brinquedos para que as crianças desenvolvam os papéis, visto que o jogo não acontece de maneira espontânea. $O$ objetivo desse jogo é a atenção sobre as atividades. Sendo assim, o conteúdo que exerce significado no desenvolvimento do jogo pelas crianças são as ações. A função do professor não está apenas em propiciar objetos para essas atividades, mas em proporcionar condições para que as crianças tenham ricos conteúdos para a sua atividade lúdica.

O processo de constituição e desenvolvimento da brincadeira é resultante da prática e das ações dos adultos que circundam a criança. Sendo assim, a atividade lúdica, dentre elas o jogo de papéis, não ocorre somente porque a criança gosta de brincar ou porque essa atividade é prazerosa e divertida; ela provém, sobretudo, da necessidade que a criança tem de agir no mundo real (DE JESUS MOYA; SFORNI; MOYA, 2019, p. 130).

Gobbo (2018) analisa o desenvolvimento da imaginação das crianças por meio das ações de desenhar e de brincar, representando os papéis sociais. $O$ autor constatou que os gêneros discursivos da cultura literária ficcional proporcionam novas experiências às crianças e o domínio de novos signos, além de ampliar as imagens subjetivas que se convertem em linguagem e pensamento, alterando os temas e conteúdos que aparecem nos desenhos e na brincadeira de papéis sociais. Sendo assim, foi possível perceber que esse trabalho com o desenvolvimento da imaginação promove novas 
experiências e aprendizagem às crianças durante a brincadeira de papéis sociais. Dessa forma, compreendemos que "Não basta, todavia, o tempo e o espaço para brincar. É preciso atenção também para o conteúdo dos jogos de papéis. Se as crianças têm na atividade humana o conteúdo para esse tipo de jogo infantil, propiciar a elas o conhecimento de vários tipos de atividades é um meio de enriquecê-los" (DE JESUS MOYA; SFORNI; MOYA, 2019, p. 132).

Ambra (20I8) pesquisa a relevância dos dados oferecidos pelo ChIPPA (Child Initiated Pretend Play Assessment), um instrumento de avaliação do faz de conta para a Educação Infantil. Os resultados apontam que esse instrumento pode orientar a ação docente, pois indica diferentes níveis no brincar de faz de conta, podendo contribuir para o desenvolvimento infantil. A pesquisa demonstra, ainda, a necessidade de ampliar o tempo e a qualidade das brincadeiras na infância, bem como propor situações de faz de conta, e analisar como essas brincadeiras são desenvolvidas.

A partir da discussão apresentada nas dissertações e teses, fica evidente a importância do brincar na pré-escola. As vivências e experiências que são desenvolvidas nesse espaço são de extrema importância para que a criança se aproprie da cultura de diversas formas, principalmente em relação ao meio social.

\footnotetext{
A percepção dessas diferentes formas de aprender ao longo da infância deve orientar a organização de vivências para buscar a melhor maneira de ensinar - e a melhor maneira das crianças aprenderem. Essas questões apontam para o fato de que a criança pequena aprende de um jeito diferente dos adultos e, portanto, o/a professor/a de criança pequena não ensina como o/a professor/a dos grandes (MELLO, 2015, p. 8).
}

Nesse sentido, ressaltamos a importância dos estudos referentes às especificidades da Educação Infantil. Nesta pesquisa, destacamos que a maior parte dos trabalhos encontrados utiliza como referencial a Teoria Histórico-Cultural, enfatizando concepções e conceitos para uma atuação crítica e consciente do profissional da escola da infância. Trata-se de uma teoria capaz de orientar a ação docente a partir de suas contribuições para a aprendizagem, o desenvolvimento e o papel da escola nesse processo.

\section{Considerações finais}

A compreensão do brincar como direito fundamental da infância em seu processo de humanização e a brincadeira de faz de conta na Educação Infantil são discussões relevantes para o desenvolvimento das crianças e a ampliação dos seus repertórios, justificando-se, assim, a escolha da temática para o desenvolvimento desta pesquisa. 
Ao invés de encurtar a infância por meio de práticas educativas que antecipam a escolarização, é preciso aperfeiçoar essas práticas para garantir, em cada idade da criança, as vivências necessárias para o desenvolvimento que está em formação na idade pré-escolar (MELLO, 20I5). O brincar de faz de conta é uma forma de aprendizagem muito importante na pré-escola, resultado das relações entre as crianças, as pessoas mais experientes e o mundo ao seu redor. Na Educação Infantil, podem ser desenvolvidas relações que auxiliam a criança na compreensão do mundo, mediante a apropriação da cultura.

\begin{abstract}
Reiteramos que no jogo de papéis as condições mais importantes e necessárias para promover as mudanças no desenvolvimento psíquico da criança encontram-se no círculo das relações sociais, na interação que a criança estabelece com as pessoas mais experientes. Nesse âmbito, é essencialmente da apropriação da cultura que surgem as possibilidades do desenvolvimento dos sujeitos (DE JESUS MOYA; SFORNI; MOYA, 2019, p. 130).
\end{abstract}

Percebe-se que, através da brincadeira de faz de conta, a criança utiliza e ativa os processos de imaginação, pensamento, linguagem, criação, além de estabelecer relações e desenvolver a função social de utilizar um objeto para representar outro, ressignificando-o e contribuindo para o seu processo de humanização e desenvolvimento.

A partir das pesquisas apresentadas neste trabalho, observamos a ausência de momentos qualitativos que possibilitem a expressão, o criar, o pensar e as relações sociais por meio das brincadeiras. Desse modo, torna-se necessário repensar as propostas desenvolvidas na Educação Infantil, para assim criar meios e condições que promovam o desenvolvimento infantil.

Para concretizar esse compromisso, é preciso ter clareza sobre a importância da intervenção intencional e consciente do professor como aquele que dirige o processo educativo, pois a criança não pode compreender o mundo sozinha. É o professor que organiza a atividade da criança e lhe apresenta 0 mundo. E sua intervenção se faz fundamental também no contexto da brincadeira de papéis (PASQUALINI, 2013, p. 90-91).

Ao defender a criança como sujeito de direitos, destacamos a necessidade de pesquisas, estudos e proposições que garantam a efetivação do direito de brincar na Educação Infantil. Nesse sentido, os estudos da Teoria Histórico-Cultural apresentam-se como um referencial pertinente para pensar o brincar e suas possibilidades na infância.

\title{
Referências
}

ABOUD, L. O. Os cantos estão arrumados. e agora, professora? $O$ papel docente nas brincadeiras de faz de conta com crianças da Educação Infantil. 2018. 9| p. Dissertação (Programa de Pós-Graduação em Educação) - Pontifícia Universidade Católica de Campinas, Campinas-SP, 2018.

Olhar de professor, Ponta Grossa, v. 24, p. I-19, e-15956.007, 2021.

Disponível em <https://revistas2.uepg.br/index.php/olhardeprofessor> 
AMBRA, K. A avaliação da brincadeira de faz de conta por meio do ChIPPA: perspectivas para a prática pedagógica na Educação Infantil. 2018. 207 p. Tese (Doutorado em Educação: Psicologia da Educação) - Pontifícia Universidade Católica de São Paulo, São Paulo, 2018.

BRASIL. Ministério da Educação. Secretaria de Educação Básica. Diretrizes Curriculares Nacionais para a Educação Infantil. Brasília: MEC/SEB, 2010.

BRASIL. Lei $n^{\circ}$ 12.796, de 4 de abril de 2013. Altera a Lei de 20 de dezembro de 1996. Brasília. DF. 2013. Disponível em: <http://www.planalto.gov.br/CCIVIL_03/_Ato20I I20I4/20I3/Lei/LI2796.htm>. Acesso em: 10 jun. 2016.

CAMPOS, M. M.; ROSEMBERG, F. Critérios para um atendimento em creches que respeite os direitos fundamentais das crianças. Brasília, DF: MEC/SEB, 2009. Disponível em: http://portal.mec.gov.br/dmdocuments/direitosfundamentais.pdf. Acesso em: 8 ago. 2019.

COSTA, S. A. da; MELLO, S. A. M. (Orgs.). Teoria Histórico-Cultural na Educação Infantil: conversando com professoras e professores. I. ed. Curitiba: CRV, 2017.

COUTO, N. S. O papel regulador da linguagem no jogo de papéis: alunos na escola, crianças na vida. 2013. 292 p. Tese (Doutorado em Educação) - Faculdade de Filosofia e Ciências de Marília, Universidade Estadual Paulista Júlio de Mesquita Filho, Marília, 2013.

GALVÃO, C. M.; SAWADA, N. O.; TREVIZAN, M. A. Revisão sistemática: recurso que proporciona a incorporação das evidências na prática da enfermagem. Revista Latino-americana de Enfermagem, [s.I.], v. I2, n. 3, p. 549-556, 2004.

GIL, A. C. Como classificar as pesquisas. In: GIL, A. C. Como elaborar projetos de pesquisa. 4. ed. São Paulo: Atlas, 2002.

GOBBO, G. R. R. O desenvolvimento da imaginação infantil mediado por gêneros discursivos e objetivado em desenhos e brincadeiras de papéis sociais. 2018. 291 p. Tese (Doutorado em Educação) - Faculdade de Filosofia e Ciências, Universidade Estadual Paulista (Unesp), Marília, 2018.

GRACILIANO. E. C. Organização do ensino pré-escolar: o que dizem as pesquisas da teoria histórico-cultural? 20I4. I26 p. Dissertação (Mestrado em Educação) - Universidade Estadual de Maringá, Maringá, 2014.

LAZARETTI, L. M.; MELLO, M. A. Como ensinar na educação infantil? Reflexões sobre a didática e o desenvolvimento da criança. In: PASQUALINI, J. C.; TEIXEIRA L. A.; AGUDO, M. M. (Orgs.). Pedagogia Histórico-Crítica: Legado e Perspectivas. I. ed. Uberlândia: Navegando, 2018.

LEONTIEV, A. Uma contribuição à teoria do desenvolvimento da psique infantil. In: VIGOTSKII, L. S.; LURIA, A. R.; LEONTIEV, A. Linguagem, desenvolvimento e aprendizagem. Tradução: Maria da Penha Villa Lobos. II. ed. São Paulo: Ícone, 20I0b.

LIMA, E. A. de; AKURI, J. G. M.; VALIENGO, A. Brincadeiras na Educação Infantil: possibilidade de humanização e direito fundamental da criança. Zero-a-seis, [s.I.], v. 20, n. 38, p. 360-374, 2018.

MANICA, A. P. Brincar/jogo de papéis sociais e a educação infantil à luz da psicologia histórico-cultural. 2018.93 p. Dissertação (Mestrado em Educação) - Universidade Federal de Goiás, Catalão, 2018. 
MARCOLINO, S. A mediação pedagógica na educação infantil para o desenvolvimento da brincadeira de papéis sociais. 2013. 185 p. Tese (Doutorado em Educação) - Faculdade de Filosofia e Ciências de Marília, Universidade Estadual Paulista, 2013.

MELLO, S. A. Infância e humanização: algumas considerações na perspectiva histórico-cultural. Perspectiva, Florianópolis, v. 25, n. I, p. 83-104, 2007.

MELLO, S. A. Contribuições da teoria histórico-cultural para a educação da pequena infância. Cadernos de Educação, [s.l.], n. 50, p. 0I-I2, 2015.

MELLO, S. A. Bebês e crianças pequenininhas como sujeitos: participação e escuta. In: COSTA, S. A. da; MELLO, S. A. (Orgs.). Teoria Histórico-Cultural na Educação Infantil: conversando com professoras e professores. I. ed. Curitiba: CRV, 2017.

MOYA, D. de J.; SFORNI, M. S. de F.; MOYA, P. T. Temas e conteúdo do jogo de papéis: sinalizando caminhos para a atuação pedagógica com a atividade lúdica na educação infantil. Revista Contexto \& Educação, [s.l.], v. 34, n. 109, p. 121-133, 2019.

NOGUEIRA, A. A. Compreendendo o desenvolvimento da fala no interior da creche. In: COSTA, S. A. da; MELLO, S. A. (Orgs.). Teoria Histórico-Cultural na Educação Infantil: conversando com professoras e professores. I. ed. Curitiba: CRV, 2017.

PASQUALINI, J. C. A perspectiva histórico-dialética da periodização do desenvolvimento infantil. Psicologia em Estudo, Maringá, v. I4, n. I, p. 31-40, jan./mar. 2009.

PASQUALINI, J. C. Periodização do desenvolvimento psíquico à luz da escola de Vigotski: a teoria histórico-cultural do desenvolvimento infantil e suas implicações pedagógicas. In: MARSIGLIA, A. C. G. Infância e pedagogia histórico-crítica. Campinas: Autores Associados, 2013.

PASQUALINI, J. C.; TEIXEIRA, L. A.; AGUDO, M. de M. Pedagogia Histórico-crítica: legado e perspectivas. In: LAZARETTI, L. M.; MELLO, M. A. Como ensinar na educação infantil? Reflexões sobre a didática e o desenvolvimento da criança. Uberlândia: Navegando Publicações, 2018.

SILVA, M. A. da. O brincar de faz de conta da criança com autismo: um estudo a partir da perspectiva histórico-cultural. 2017. I 33 f. Dissertação (Mestrado em Processos de Desenvolvimento Humano e Saúde) - Universidade de Brasília, Brasília, 2017.

Recebido em: 13 de junho de 2020.

Aceito em: 30 de setembro de 2020.

Versão final recebida em: 09 de dezembro de 2020.

Publicado online em: 12 de março de 2021.

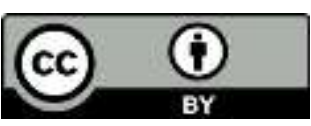

Olhar de professor, Ponta Grossa, v. 24, p. I-19, e-15956.007, 2021.

Disponível em <https://revistas2.uepg.br/index.php/olhardeprofessor> 